\title{
Ophiopogonin-B targets PTP1B to inhibit the malignant progression of hepatocellular carcinoma by regulating the PI3K/AKT and AMPK signaling pathways
}

\author{
FANG YUAN*, QIAN GAO*, HAILIN TANG, JUN SHI and YIQUN ZHOU \\ Department of Liver Disease, Suzhou Hospital of Integrated Traditional Chinese and Western Medicine, \\ Suzhou, Jiangsu 215101, P.R. China
}

Received November 10, 2021; Accepted December 23, 2021

DOI: $10.3892 / \mathrm{mmr} .2022 .12638$

\begin{abstract}
Ophiopogonin-B (OP-B) is a bioactive component from the root of Ophiopogon japonicus, which can exert anticancer effects on multiple malignant tumors. The present study aimed to uncover the effects of OP-B on hepatocellular carcinoma (HCC) and the underlying mechanisms. An HCC-xenografted mouse model was established and subsequently treated with OP-B (15 and $75 \mathrm{mg} / \mathrm{kg}$ ) to observe the effects of OP-B on HCC progression and protein tyrosine phosphatase 1B (PTP1B) expression in vivo. The HCC cell line MHCC97-H was transfected with either PTP1B overexpression (Ov)-PTP1B or empty vector control, and then exposed to different concentrations of OP-B. Subsequently, PTP1B expression, cell viability, proliferation, apoptosis, migration, invasion and angiogenesis were evaluated by western blotting, reverse transcription-quantitative PCR, Cell Counting Kit-8, colony formation, TUNEL staining, wound healing, Transwell and tube formation assays. The expression of phosphatidylinositol 3 kinase (PI3K)/AKT and adenosine 5'-monophosphate-activated protein kinase (AMPK) was also assessed by western blot assay. The results showed that OP-B inhibited tumor growth and the expression of Ki67, CD31, VEGFA and PTP1B in HCC xenograft model. The expression of PTP1B in HCC cells was also inhibited by OP-B in a concentration-dependent manner. Results from the in vitro studies revealed that OP-B suppressed cell proliferation, migration, invasion and angiogenesis, and promoted apoptosis
\end{abstract}

Correspondence to: Dr Jun Shi or Dr Yiqun Zhou, Department of Liver Disease, Suzhou Hospital of Integrated Traditional Chinese and Western Medicine, 39 Xiashatang Street, Mudu, Wuzhong, Suzhou, Jiangsu 215101, P.R. China

E-mail: shijunsj1123@163.com

E-mail: xianyucapa@outlook.com

*Contributed equally

Key words: hepatocellular carcinoma, ophiopogonin-B, protein tyrosine phosphatase $1 \mathrm{~B}$ of HCC cells. However, PTP1B overexpression reversed the effect of OP-B on HCC cells. PI3K/AKT was inactivated and AMPK was activated by OP-B exposure in HCC cells, and PTP1B overexpression blocked these effects. In conclusion, OP-B effectively inhibited the progression of HCC both in vivo and in vitro. These effects may depend on downregulating PTP1B expression, thereby inactivating the PI3K/AKT pathway and activating the AMPK pathway.

\section{Introduction}

Liver cancer is a leading cancer that occurs most commonly and is considered as the fourth most prevalent human tumor globally (1). Owing to increasing number of new liver cancer cases, it has become major public health challenge (2). In addition, weak prognosis of major hepatic malignancies results in the increase in the rate of mortality in primary liver cancer (1). Hepatocellular carcinoma (HCC) is the most common form of liver cancer, accounting for up to $90 \%$ of all primary hepatic malignancies (3). Despite advances in medical and surgical therapies, HCC remains one of the most common causes of cancer-related deaths worldwide since therapies do not always produce optimal patient outcomes (4). Therefore, more effective treatment methods of HCC are required, particularly certain specific targeted agents.

Traditional Chinese medicine (TCM) is an important therapy for liver cancer in China. Owing to its unique overall concept, treatment based on syndrome differentiation and abundant natural medicine resources, it has become a characteristic method throughout the entire process of liver cancer prevention and treatment $(5,6)$. Ophiopogonin-B (OP-B) is a bioactive component from the root of Ophiopogon japonicus, which is widely used in TCM to treat pulmonary disease $(7,8)$. In the last decade, an increasing number of studies reported the anticancer effect of OP-B on multiple malignant tumors, including lung, colon, gastric and ovarian cancer (7-10). It was previously demonstrated that OP-B induced HCC cell apoptosis and decreased invasion through inhibition of the JAK2/STAT3 signaling pathway, indicating the potential value of OP-B in treating HCC (11). In the present study, further in vivo and in vitro studies were performed to confirm whether OP-B exhibits an inhibitory effect on the malignant processes of HCC. 
Protein tyrosine phosphatase 1B [PTP1B; encoded by protein tyrosine phosphatase non-receptor type 1 (PTPN1)] is an important member in PTP superfamily of proteins. PTPs catalyze phosphate monoesters hydrolysis on tyrosine residues; they are also known to act as signaling molecules to regulate a number of cellular processes, including cell growth, differentiation, mitotic cycle and oncogenic transformation (12). To date, PTP1B has been reported to be also involved in the development of obesity, diabetes, cancers and cardiovascular diseases (13). Recently, Xu et al (14) showed that PTPN1 was upregulated in HCC and its silencing suppressed proliferation and induced apoptosis of HCC cells. A similar result was reported by Yang et al (15), which suggested that downregulation of PTP1B inhibited HCC development. These results indicated an oncogenic role of PTP1B in HCC. Notably, it is predicted by SwissTargetPrediction online database (16) that PTPN1 (PTP1B) is one of the targets of OP-B (data not shown). Therefore, the present study aimed to investigate whether OP-B exhibited an inhibitory effect on the malignant process of HCC via targeting PTP1B.

\section{Materials and methods}

Cell culture and treatment. The human normal hepatocyte cell line HHL-5 and the HCC cell line MHCC97-H were obtained from the American Type Culture Collection. Both cell lines were cultured in DMEM (Sigma-Aldrich; Merck KGaA) supplemented with $10 \%$ fetal bovine serum (FBS; Wisent Biotechnology) and $1 \%$ penicillin-streptomycin (Sigma-Aldrich; Merck KGaA) in an incubator with $5 \% \mathrm{CO}_{2}$ at $37^{\circ} \mathrm{C}$. For OP-B treatment, cells were cultured in DMEM containing different concentrations $(5,10,20$ and $40 \mu \mathrm{M})$ of OP-B (purity >97\%; Shanghai Yuanye Bio-Technology Co., Ltd.) for $24 \mathrm{~h}$ as previously described $(8,11,17,18)$. Cells cultured in normal DMEM without OP-B were used as a control.

Cell transfection. A PTP1B overexpression vector (Ov-PTP1B) was constructed by cloning human PTP1B cDNA into the pcDNA3.1 vector (Thermo Fisher Scientific, Inc.). Empty pcDNA3.1 vector was used as negative control (Ov-NC). MHCC97-H cells were grown in six-well plates and subsequently transfected with $2 \mu \mathrm{g}$ of either vector using Lipofectamine ${ }^{\circledR} 2000$ (Invitrogen; Thermo Fisher Scientific, Inc.) at $37^{\circ} \mathrm{C}$ for $24 \mathrm{~h}$ according to the manufacturer's protocol. At $48 \mathrm{~h}$ post-transfection, monoclonal cells were then selected and examined for PTP1B overexpression.

Xenograft tumor model. A total of 15 male BALB/c nude mice (age, 4-5 weeks; 15-20 g; Shanghai Laboratory Animal Center) were maintained under specific pathogen-free conditions at room temperature under a controlled 12/12 h light/dark cycle, and received food and water ad libitum. The animal study protocol was approved by the Ethics Committee of Suzhou Hospital of Integrated Traditional Chinese and Western Medicine (Suzhou, China; approval no. 20180901). To establish the HCC xenograft model, MHCC97-H cells $\left(2 \times 10^{6}\right.$ cells $\left./ 200 \mu \mathrm{l}\right)$ were subcutaneously injected into the right flank of the nude mice. After six days, mice were treated by oral gavage with normal saline (control group; $\mathrm{n}=5$ ), $15 \mathrm{mg} / \mathrm{kg}$ OP-B (OP-B 15 mg/kg group; $\mathrm{n}=5$ ) or $75 \mathrm{mg} / \mathrm{kg}$ OP-B (OP-B
$75 \mathrm{mg} / \mathrm{kg}$ group; $\mathrm{n}=5$ ) once a day for 21 days, as previously described $(8,17,18)$. Mouse body weight and tumor volume were recorded every 7 days; at 21 days post-treatment, the mice were sacrificed by cervical dislocation under anesthesia with $1 \%$ sodium pentobarbital (50 mg/ $\mathrm{kg}$ intraperitoneally). Tumor volumes for each mouse were calculated as follows: Tumor volume $=1 / 2 \times$ length $\mathrm{x}$ width ${ }^{2}$.

Immunohistochemistry (IHC). Xenografted tumor tissues were fixed with $4 \%$ paraformaldehyde at $4{ }^{\circ} \mathrm{C}$ for $12 \mathrm{~h}$ and embedded in paraffin. After being deparaffinized with xylene and rehydrated with a descending ethanol series, slides (3 $\mu \mathrm{m}$ thickness) were stained with the IHC Assay Kit (cat. no. KGOS300; Nanjing KeyGen Biotech Co., Ltd.) according to the manufacturer's protocol and then incubated at $4^{\circ} \mathrm{C}$ overnight with the following primary antibodies purchased from Abcam: Anti-Ki67 (1:1,000; cat. no. ab15580), anti-CD31 (1:50; cat. no. ab28364) and anti-VEGFA (1:200; cat. no. ab52917). Secondary antibody goat anti-rabbit IgG (1:1,000; cat. no. ab6721; Abcam) was applied at room temperature for $2 \mathrm{~h}$. Images of the tissue sections were then captured with a fluorescence microscope (DMi8; Leica Microsystems GmbH; x200 magnification).

Cell viability. Cell Counting Kit-8 (CCK8; Beyotime Institute of Biotechnology) was used to measure cell viability. Briefly, cells were seeded into 96-well plates at a density of 1,000 cells $/$ well at $37^{\circ} \mathrm{C}$ for $24 \mathrm{~h}$. After treatment with different concentrations of OP-B $(0,5,10,20$ and $40 \mu \mathrm{M})$ at $37^{\circ} \mathrm{C}$ for $24 \mathrm{~h}$, cells were incubated with $10 \mu \mathrm{l}$ of CCK-8 solution at $37^{\circ} \mathrm{C}$ for $2 \mathrm{~h}$. The optical density was calculated at $450 \mathrm{~nm}$ using a microplate reader (Model550; Bio-Rad Laboratories, Inc.).

Colony formation. For the colony formation assay, $1 \times 10^{3}$ MHCC97-H cells were cultivated in six-well plates in a $37^{\circ} \mathrm{C}$ incubator with $5 \% \mathrm{CO}_{2}$. After 14 days, cell colonies were fixed with $95 \%$ alcohol at room temperature for $30 \mathrm{~min}$ and stained with $0.1 \%$ crystal violet at room temperature for 30 min (Sigma-Aldrich; Merck KGaA). Images were captured with a light microscope (Nikon Corporation; x200 magnification) and colonies were counted using ImageJ software (version 1.8.0; National Institutes of Health).

TUNEL staining. According to the manufacturer's protocol, MHCC97-H cell apoptosis was analyzed using TUNEL Assay kit (Abcam). Briefly, cells were fixed in 4\% paraformaldehyde solution for $30 \mathrm{~min}$ at room temperature, treated with $0.2 \%$ Triton $\mathrm{X}-100$ for $5 \mathrm{~min}$ at room temperature, washed twice in PBS at room temperature, and labeled with fluorescein-12-dUTP using terminal deoxynucleotidyl transferase for $2 \mathrm{~h}$ at room temperature. Subsequently, cell nuclei were stained with $5 \mu \mathrm{g} / \mathrm{ml}$ DAPI at room temperature for $3 \mathrm{~min}$. All images were obtained using a fluorescence microscope (DMi8; Leica Microsystems GmbH; x200 magnification).

Wound healing assay. Briefly, MHCC97-H cells were seeded in a six-well plate at a density of $5 \times 10^{5}$ cells/well in DMEM. When the cells were $\sim 80 \%$ confluent, scratches were made in the middle of slides using a sterile $10-\mu 1$ pipette tip. After incubation for another $48 \mathrm{~h}$ with or without $20 \mu \mathrm{M}$ OP-B in 
serum-free DMEM at $37^{\circ} \mathrm{C}$, images were captured to estimate closure of the gap using a light microscope (Nikon Corporation; x200 magnification). Migration distance was evaluated using ImageJ software (version 1.8.0; National Institutes of Health) and calculated as follows: Migration distance $=$ (width of gap at $0 \mathrm{~h}$-width of gap at $48 \mathrm{~h}$ )/width of gap at $0 \mathrm{~h}$. Data are shown as relative migration distance by normalization to the control group.

Transwell invasion assay. The invasive ability of MHCC97-H cells was evaluated by the Biocoat invasion assay kit (Corning, Inc.) strictly following the manufacturer's protocol. Firstly, $5 \times 10^{5}$ cells per well were plated in the upper chamber followed by treatment with $20 \mu \mathrm{M}$ OP-B or not. After $12 \mathrm{~h}$ of treatment, the cells in the upper chamber were incubated with serum-free DMEM medium, whereas media supplemented with $10 \%$ FBS was placed at the lower chamber. After $48 \mathrm{~h}$, the invasive cells at the lower chamber were stained with $0.1 \%$ crystal violet at room temperature and observed using an optical light microscope (Leica Microsystems GmbH; x200 magnification).

Tube formation assay. Matrigel (BD Biosciences) was thawed at $4^{\circ} \mathrm{C}$, pipetted into 96 -well plates and allowed to polymerize at $37^{\circ} \mathrm{C}$ for $1 \mathrm{~h}$. Cells $\left(1 \times 10^{4}\right.$ per well) were suspended in DMEM containing 0 or $20 \mu \mathrm{M}$ OP-B and seeded onto the Matrigel. After incubation for $24 \mathrm{~h}$ at $37^{\circ} \mathrm{C}$, tube formation was analyzed by counting nodes and measuring total tube numbers using ImageJ software (version 1.8.0; National Institutes of Health).

Reverse transcription-quantitative PCR (RT-qPCR). Total RNA was extracted using TRIzol ${ }^{\circledR}$ (Invitrogen; Thermo Fisher Scientific, Inc.), according to the manufacturer's protocol, and then reverse transcribed into cDNA using a High Capacity cDNA Reverse Transcription Kit (Applied Biosystems) according to the manufacturer's protocol. SYBR-Green Supermix (Takara Biotechnology Co., Ltd.) was used for qPCR in a $10 \mu 1$ reaction volume on the Roche Light Cycler R480 System (Roche Diagnostics). The following thermocycling conditions were used for the qPCR: Initial denaturation at $95^{\circ} \mathrm{C}$ for $30 \mathrm{sec}$; followed by 40 cycles of denaturation at $95^{\circ} \mathrm{C}$ for $10 \mathrm{sec}$, annealing at $60^{\circ} \mathrm{C}$ for $20 \mathrm{sec}$ and extension at $70^{\circ} \mathrm{C}$ for $10 \mathrm{sec}$. Target gene expression levels were analyzed using the $2^{-\triangle \Delta \mathrm{Cq}}(19)$ method and normalized to GAPDH. The primers used for RT-qPCR were as follows: PTP1B forward, 5'-CCAGCCAAAGGGGAGCCGTC-3' and reverse, 5'-CTA TGTGTTGCTGTTGAACA-3'; and GAPDH forward, 5'-AAT GGGCAGCCGTTAGGAAA-3' and reverse, 5'-GCGCCC AATACGACCAAATC-3'

Western blot assay. Total protein was extracted from cells or tumor tissues by RIPA lysis buffer (Beyotime Institute of Biotechnology). Total protein was quantified using a BCA Kit (Beyotime Institute of Biotechnology), mixed with 5X sample buffer and boiled at $95^{\circ} \mathrm{C}$ for $5 \mathrm{~min}$. Equal amounts $(40 \mu \mathrm{g})$ of protein lysate per sample were separated on $10 \%$ gels using SDS-PAGE and transferred onto the PVDF membranes. After blocking with $5 \%$ skimmed milk for $2 \mathrm{~h}$ at room temperature, membranes were incubated with primary antibodies at $4^{\circ} \mathrm{C}$ overnight and secondary antibodies (goat anti-rabbit IgG HRP; 1:10,000; cat. no. ab6721; Abcam) at room temperature for $2 \mathrm{~h}$. An enhanced chemiluminescence (ECL) detection kit (Amersham; Cytiva) was used to visualize the protein bands. Band intensity was semi-quantified by Image J software (v1.8.0; National Institutes of Health). Primary antibodies (all from Abcam) included: anti-PTP1B (1:1,000; cat. no. ab252928), anti-Bcl-2 (1:1,000; cat. no. ab32124), anti-Bax (1:5,000; cat. no. ab32503), anti-cleaved caspase 3 (1:500; cat. no. ab32042), anti-caspase-3 (1:1,000; cat. no. ab184787), anti-cleaved poly ADP-ribose polymerase (PARP; 1:5,000; cat. no. ab32064), anti-PARP (1:5,000; cat. no. ab191217), anti-E-cadherin (1:10,000; cat. no. ab40772), anti-N-cadherin (1:10,000; cat. no. ab76011), anti-Vimentin (1:1,000; cat. no. ab45939), anti-VEGFA (1:10,000; cat. no. ab52917), anti-phosphorylated (p)-phosphatidylinositol 3 kinase (PI3K; 1:1,000; cat. no. ab191606), anti-total (t)-PI3K (1:1,000; cat. no. ab278545), anti-p-AKT (1:1,000; cat. no. ab38449), anti-t-AKT (1:1,000; cat. no. ab8805), anti-p-adenosine 5'-monophosphate-activated protein kinase (AMPK; 1:1,000; cat. no. ab109402), anti-t-AMPK (1:1,000; cat. no. ab214425) and anti-GAPDH (1:10,000; cat. no. ab181602).

Statistical analysis. Data are expressed as the mean \pm standard deviation. One-way ANOVA followed by Tukey's post hoc test was used for analysis between multiple groups. Calculations were performed using GraphPad Prism software (version 5.0; GraphPad Software, Inc.). $\mathrm{P}<0.05$ was considered to indicate a statistically significant difference.

\section{Results}

$O P-B$ inhibits tumor growth and $P T P 1 B$ expression in $H C C$ xenografted mice. The anticancer effects of OP-B on HCC were first investigated in vivo. HCC xenografts were injected into mice (Fig. 1A) that were subsequently treated orally with 0 , 15 or $75 \mathrm{mg} / \mathrm{kg}$ OP-B. Tumor volume and mouse body weight were examined for 21 days (Fig. 1B). The tumors were excised (Fig. 1C) and the final tumor weight and the tumor/body weight ratio were measured.(Fig. 1D), which were significantly reduced in mice treated with both 15 and $75 \mathrm{mg} / \mathrm{kg}$ OP-B compared with the control mice. Additionally, it was observed from IHC results that the expression level of Ki67 (Fig. 1E), CD31 (Fig. 1F) and VEGFA (Fig. 1G) in HCC tumor tissues of the xenografted mice was markedly decreased upon OP-B (15 and $75 \mathrm{mg} / \mathrm{kg}$ ) administration compared with the control mice. In addition, the mRNA and protein expression levels of PTP1B in tumor samples of xenograft mice model was significantly inhibited by OP-B (Fig. 1H and I, respectively). These results showed that $\mathrm{OP}-\mathrm{B}$ exerted anticancer effect on $\mathrm{HCC}$ in vivo.

$O P-B$ reduces cell viability and $P T P 1 B$ expression in $H C C$ cells. To validate the effect of OP-B on HCC and PTP1B expression in vitro, HHL-5 human normal hepatocyte and MHCC97-H HCC cells were exposed to different concentrations of OP-B $(5,10,20$ and $40 \mu \mathrm{M})$ for $24 \mathrm{~h}$, then cell viability was measured. As revealed in Fig. 2A, OP-B treatment did not cause significant effect on HHL-5 cell viability, but significantly reduced MHCC97-H cell viability in a concentration-dependent manner. In addition, both the mRNA and the protein expression levels of PTP1B were significantly downregulated by OP-B (Fig. 2B and C, respectively). 
A

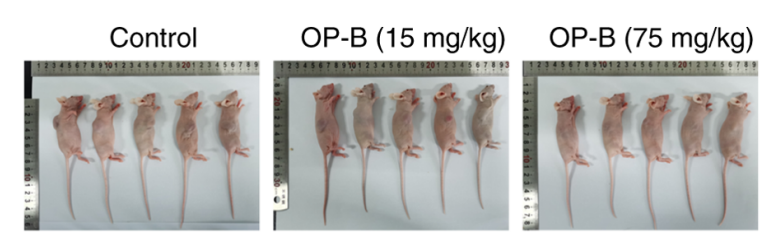

B

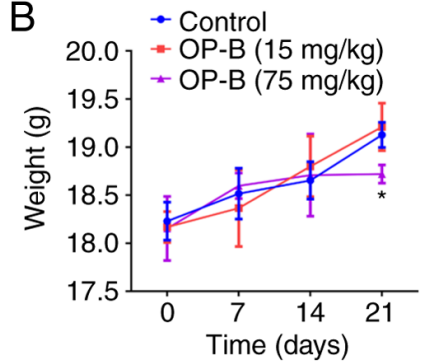

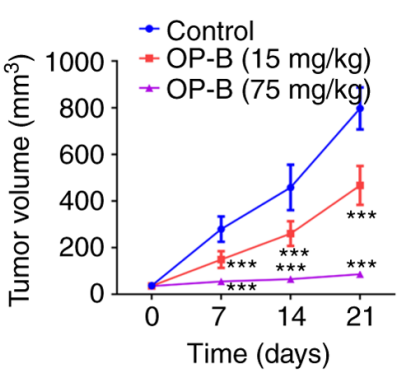

C
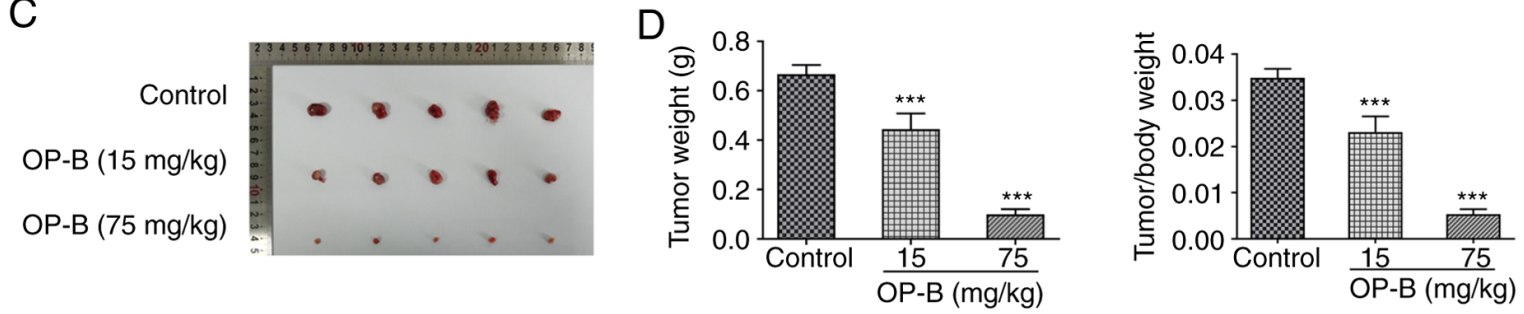

E

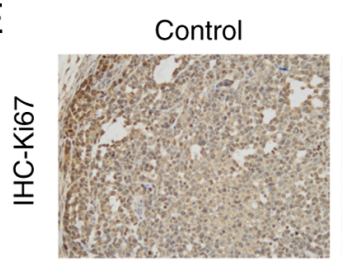

F

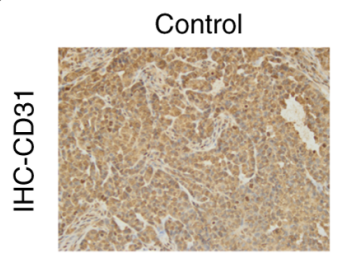

G

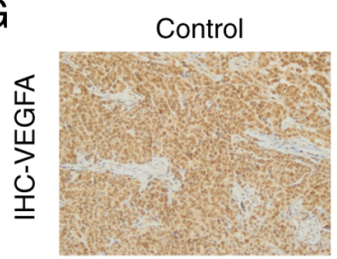

OP-B $(15 \mathrm{mg} / \mathrm{kg})$
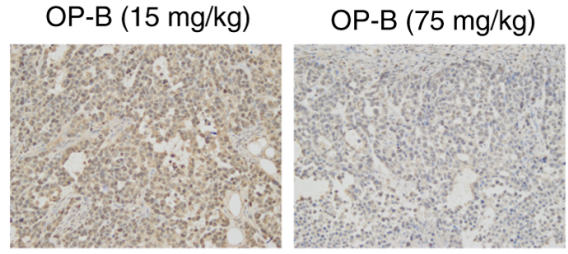

OP-B $(15 \mathrm{mg} / \mathrm{kg})$

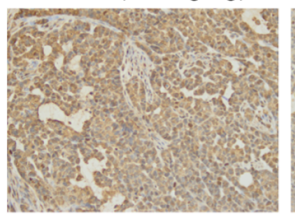

OP-B (15 mg/kg)

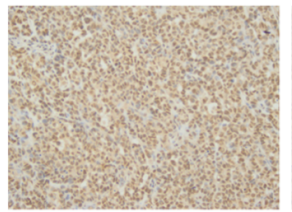

OP-B $(75 \mathrm{mg} / \mathrm{kg})$

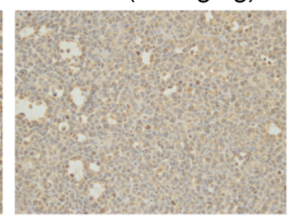

OP-B $(75 \mathrm{mg} / \mathrm{kg})$

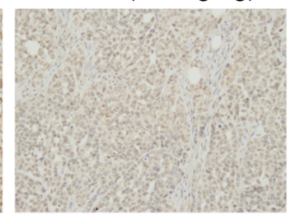

$\mathrm{H}$
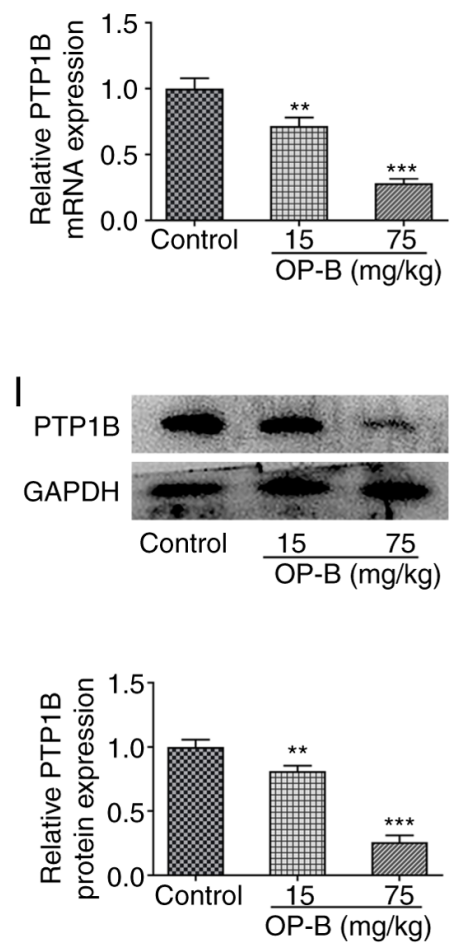

Figure 1. Effect of OP-B on HCC progression and PTP1B expression in vivo. (A) HCC xenograft mice were treated with normal saline, or with $15 \mathrm{or} 75 \mathrm{mg} / \mathrm{kg}$ OP-B for 21 days. (B) Body weight and tumor volumes were recorded every 7 days. (C) HCC tumors in different groups were removed from xenograft model and (D) weighed and the tumor/body weight was also calculated. The expression of Ki67 (E), CD31 (F) and VEGFA (G) in tumor samples of HCC xenograft mice were detected by IHC. (H) mRNA and (I) protein expression levels of PTP1B in tumor samples of HCC xenograft mice were measured by reverse transcription-quantitative $\mathrm{PCR}$ and western blot assays, respectively. ${ }^{*} \mathrm{P}<0.05,{ }^{* *} \mathrm{P}<0.01$ and ${ }^{* * *} \mathrm{P}<0.001$ vs. control. HCC, hepatocellular carcinoma; IHC, immunohistochemistry; OP-B, ophiopogonin-B; PTP1B, protein tyrosine phosphatase 1B.

Subsequently, PTP1B was overexpressed in MHCC97-H cells by transfection of Ov-PTP1B vector and then the overexpression efficiency was confirmed by RT-qPCR and western blotting (Fig. 2D and E, respectively).

Decreased PTPIB expression may be responsible for the anticancer effect of OP-B on HCC. To observe the effect of OP-B on the malignant processes of HCC, MHCC97-H cells overexpressing PTP1B were treated with $20 \mu \mathrm{M}$ OP-B, then cell proliferation, apoptosis, migration, invasion and angiogenesis were evaluated. As revealed in Fig. 3A, OP-B significantly reduced cell viability compared with the untreated control group, whereas OP-B + Ov-PTP1B treatment significantly enhanced the cell viability compared with the OP-B + Ov-NC group. These results indicated that the inhibitory effect of OP-B on HCC cell viability was reversed by PTP1B overexpression. Furthermore, OP-B markedly suppressed the colony formation compared with control MHCC97-H cells, whereas PTP1B overexpression markedly reduced this effect (Fig. 3B). TUNEL staining revealed that apoptosis was significantly increased 
A

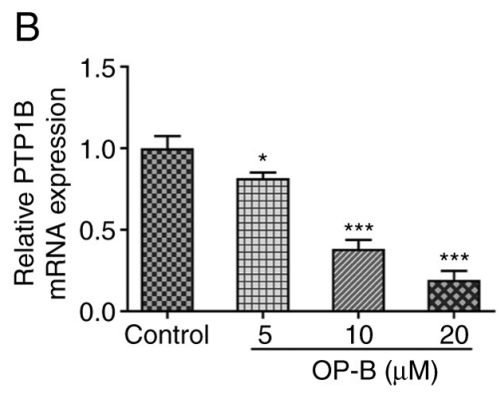

$\mathrm{D}$

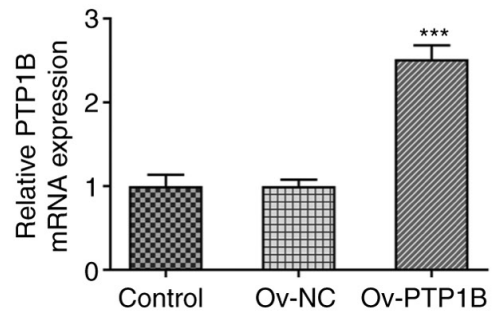

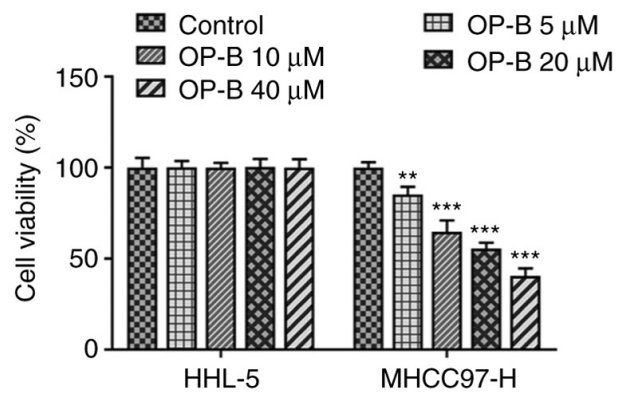

C
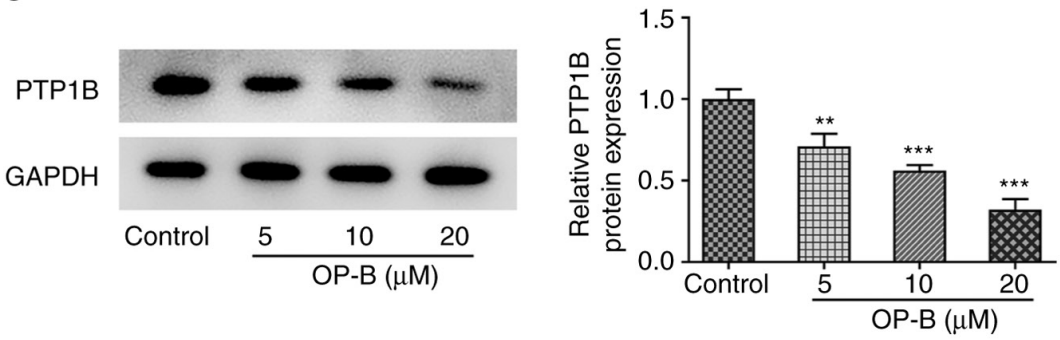

E

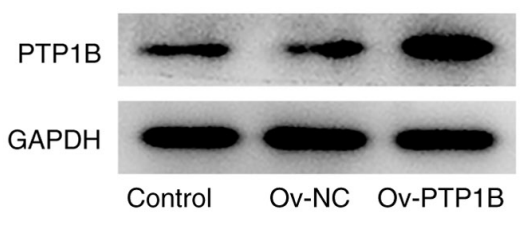

Figure 2. Effect of OP-B on PTP1B expression in hepatocellular carcinoma cells. (A) HHL-5 and MHCC97-H cells were exposed to different concentrations of OP-B for $24 \mathrm{~h}$, then cell viability was measured by Cell Counting Kit- 8 assay. MHCC97-H cells were treated with different concentrations of OP-B for $24 \mathrm{~h}$, then PTP1B (B) mRNA and (C) protein expression levels were evaluated. MHCC97-H cells were either transfected with Ov-PTP1B or empty vector, then the overexpression efficiency was verified by (D) reverse transcription-quantitative $\mathrm{PCR}$ and $(\mathrm{E})$ western blot assays. ${ }^{*} \mathrm{P}<0.05,{ }^{* *} \mathrm{P}<0.01$ and ${ }^{* * * *} \mathrm{P}<0.001 \mathrm{vs}$. control. $\mathrm{NC}$, negative control; OP-B, ophiopogonin-B; Ov, overexpression vector; PTP1B, protein tyrosine phosphatase 1B.

upon OP-B treatment compared with the control group, and PTP1B overexpression reduced the level of apoptosis compared with OP-B + Ov-NC (Fig. 3C). Consistently, OP-B treatment resulted in decreased protein expression of Bcl-2, but increased expression levels of Bax, cleaved caspase 3 and cleaved PARP, suggesting the induction of cell apoptosis (Fig. 3D). However, PTP1B overexpression caused a reverse effect on the expression of these proteins in OP-B-treated cells (Fig. 3D).

Results from wound healing, invasion and tube formation assays demonstrated that OP-B significantly inhibited MHCC97-H cell migration, invasion and angiogenesis compared with untreated control cells (Fig. 4A-C, respectively). By contrast, OP-B + Ov-PTP1B treatment significantly increased these processes compared with OP-B + Ov-NC group (Fig. 4A-C). In addition, OP-B treatment significantly increased E-cadherin expression but decreased N-cadherin, Vimentin and VEGFA expression (Fig. 4D), whereas PTP1B overexpression reversed the effect on the expression levels of these proteins caused by OP-B.

$O P-B$ inactivates the PI3K/AKT signaling and activates $A M P K$ signaling by reducing $P T P 1 B$ expression. To uncover the underlying related signaling mechanism of OP-B, the expression of the PI3K/AKT and AMPK signaling pathways was detected. As demonstrated in Fig. 5, MHCC97-H cells showed decreased $\mathrm{p} / \mathrm{t}-\mathrm{PI} 3 \mathrm{~K}$ and $\mathrm{p} / \mathrm{t}-\mathrm{AKT}$ expression levels as well as increased $\mathrm{p} / \mathrm{t}-\mathrm{AMPK}$ expression in response to OP-B treatment. Conversely, when compared with $\mathrm{OP}-\mathrm{B}+\mathrm{Ov}-\mathrm{NC}$, OP-B + Ov-PTP1B treatment significantly upregulated $\mathrm{p} / \mathrm{t}-\mathrm{PI} 3 \mathrm{~K}$ and $\mathrm{p} / \mathrm{t}-\mathrm{AKT}$ expression levels and downregulated $\mathrm{p} / \mathrm{t}-\mathrm{AMPK}$ expression. These data indicated that OP-B may inhibit PI3K/AKT activation and activate the AMPK signaling, which is supported by the data showing that these effects were blocked by PTP1B overexpression.

\section{Discussion}

OP-B is a natural active compound extracted from the TCM Ophiopogon japonicus root, which was found to exert inhibitory effect on non-small cell lung cancer cell lines (20). In the present study, OP-B was demonstrated to inhibit HCC development both in vitro and in vivo. Further experiments indicated that OP-B may exert its anticancer effect on HCC by targeting PTP1B and regulating the PI3K/AKT and AMPK signaling pathways.

Natural compounds from TCM have been revealed to exert remarkable effects in the treatment of HCC (21-24). For example, PHY906 has been reported to reduce the adverse 
A

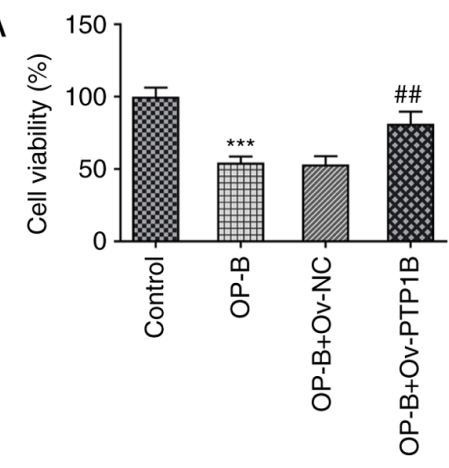

B

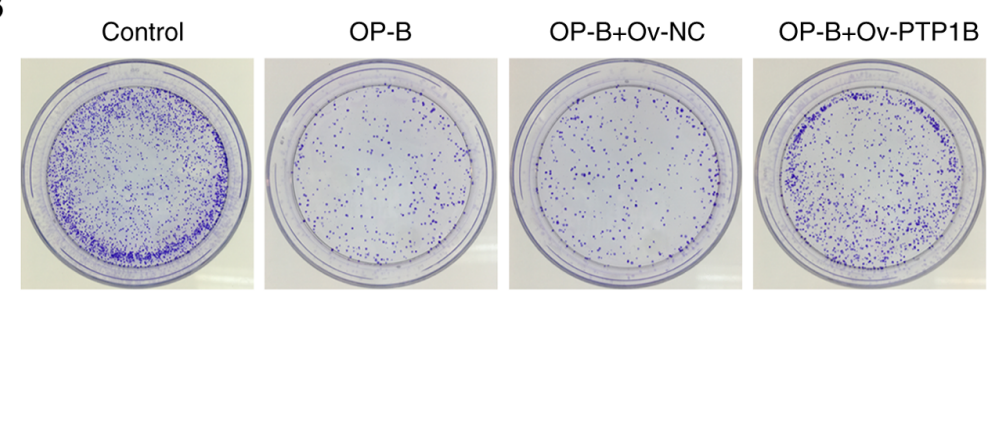

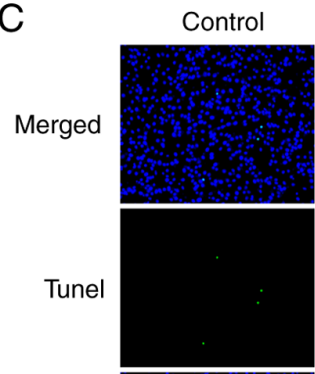

OP-B

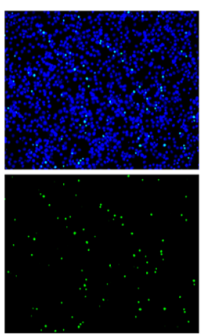

DAPI
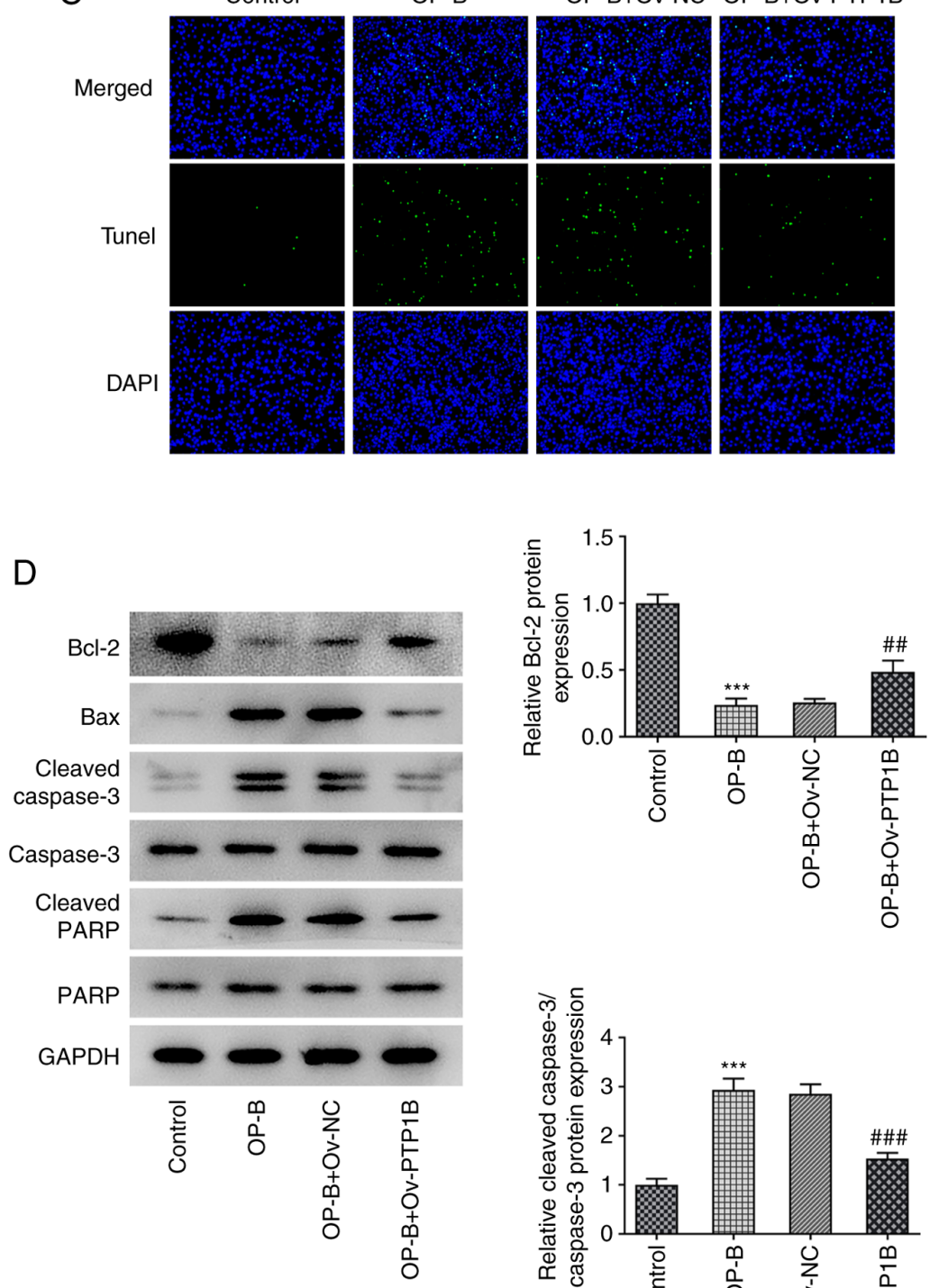
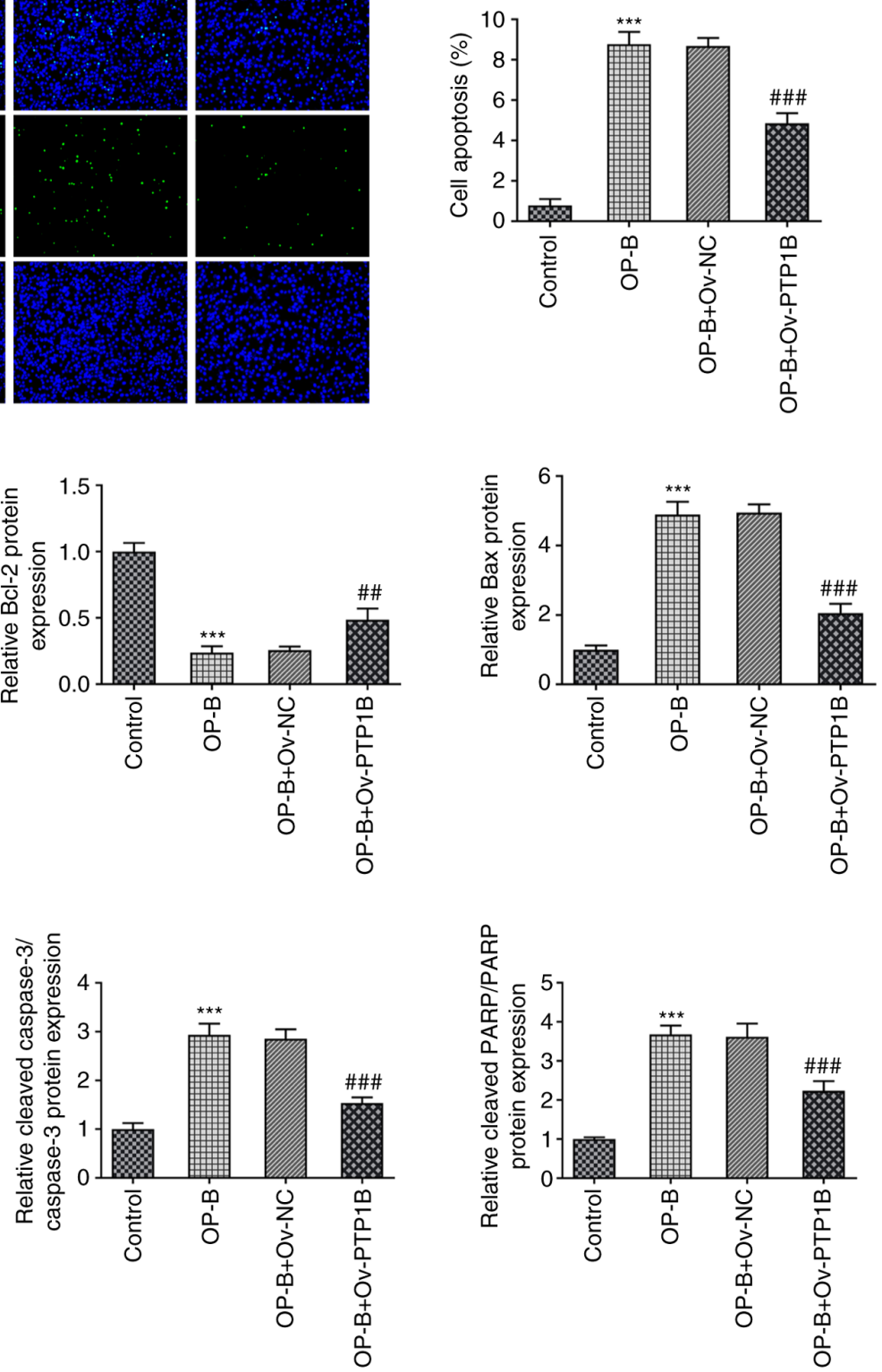

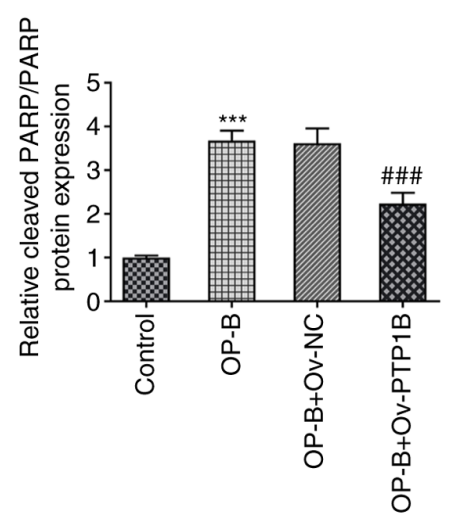

Figure 3. Effect of OP-B and PTP1B overexpression on hepatocellular carcinoma cell proliferation and apoptosis. MHCC97-H cells were transfected with Ov-PTP1B or OV-NC and subsequently treated with $20 \mu \mathrm{M}$ OP-B. (A) Cell viability was measured by Cell Counting Kit-8 assay. (B) Colony formation was performed to observe cell proliferation. (C) TUNEL staining was used to assess apoptosis. (D) Protein expression levels of apoptosis-related proteins were detected by western blotting; GAPDH was used as the loading control. ${ }^{* * *} \mathrm{P}<0.001$ vs. control; ${ }^{\# \#} \mathrm{P}<0.01$ and ${ }^{\# \# \#} \mathrm{P}<0.001$ vs. OP-B + Ov-NC. NC, negative control; OP-B, ophiopogonin-B; Ov, overexpression vector; PTP1B, protein tyrosine phosphatase 1B.

effects of capecitabine in advanced HCC patients in a phase I/II clinical study (25). These studies reflected the satisfactory curative effect and huge potential of TCM in the treatment of
HCC. In the present study, 15 and $75 \mathrm{mg} / \mathrm{kg}$ OP-B was selected for treating HCC-xenografted mice by oral gavage according to previous studies $(8,17,18)$. OP-B at these two doses had no 
A

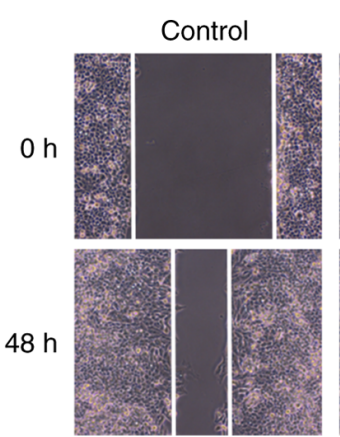

B
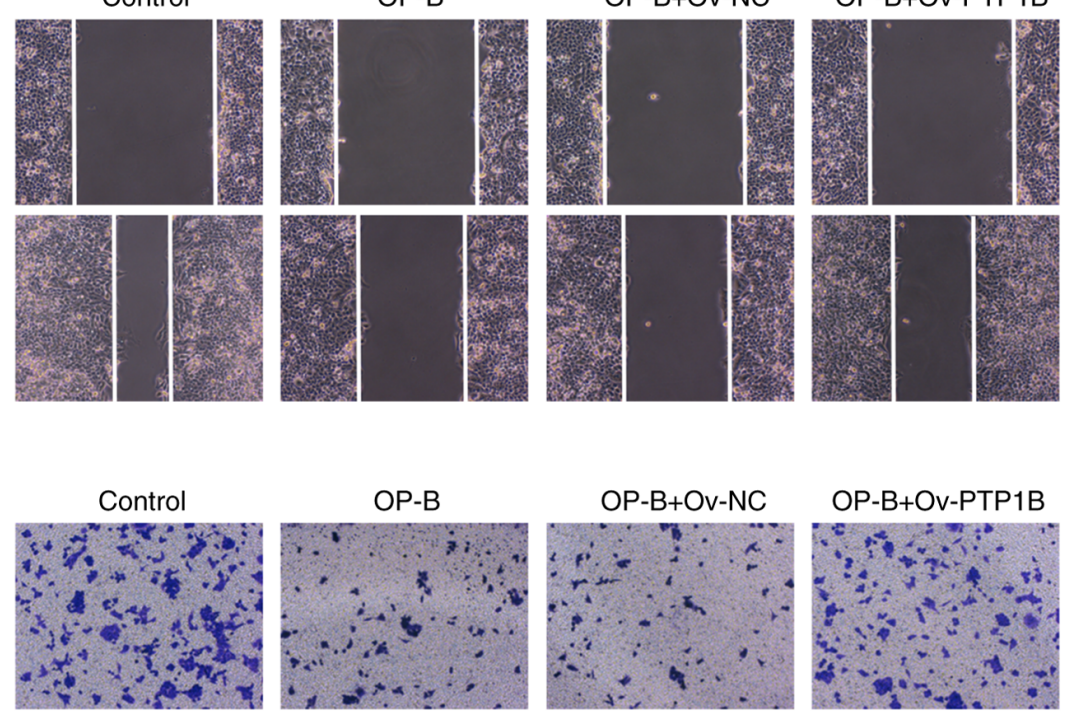

OP-B+Ov-NC
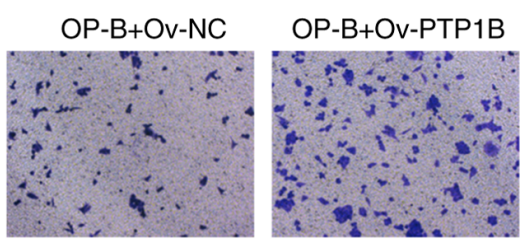

C

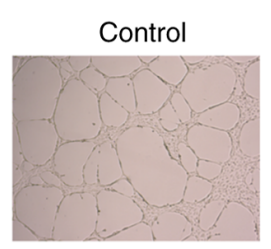

OP-B

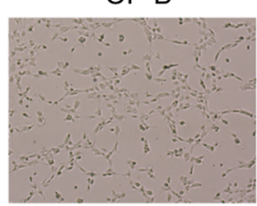

$\mathrm{OP}-\mathrm{B}+\mathrm{Ov}-\mathrm{NC}$
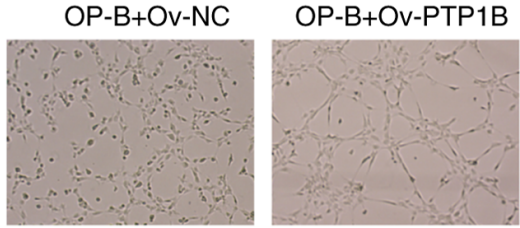

OP-B+Ov-PTP1B
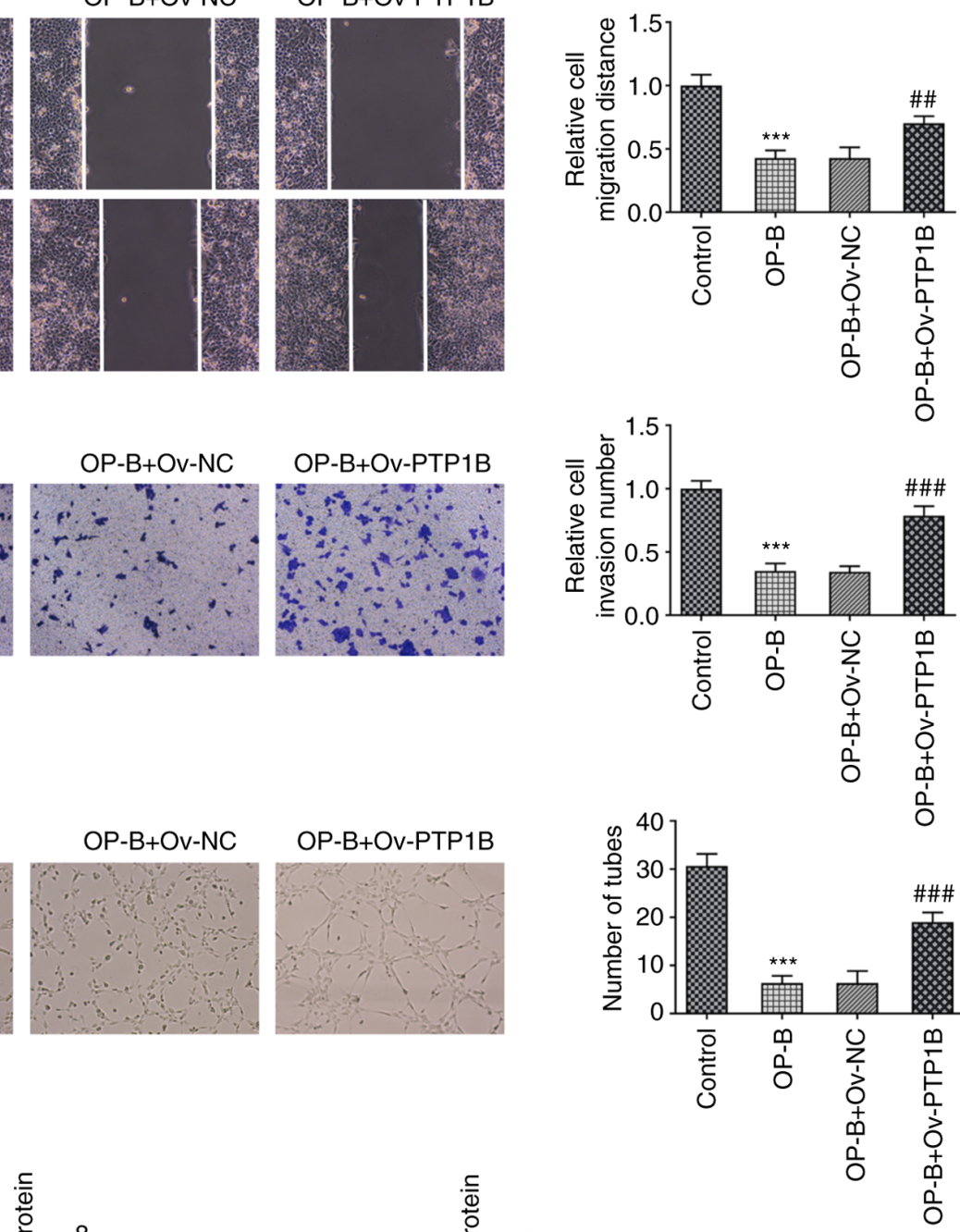

D

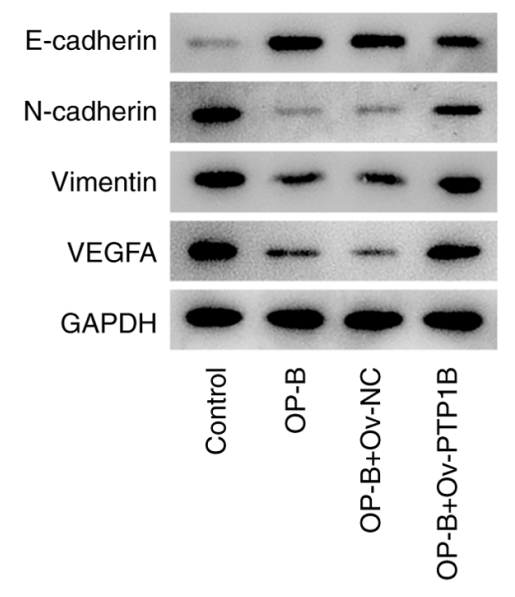

$\stackrel{\frac{\mathrm{c}}{\mathrm{d}}}{\frac{\mathrm{O}}{\mathrm{O}}}$
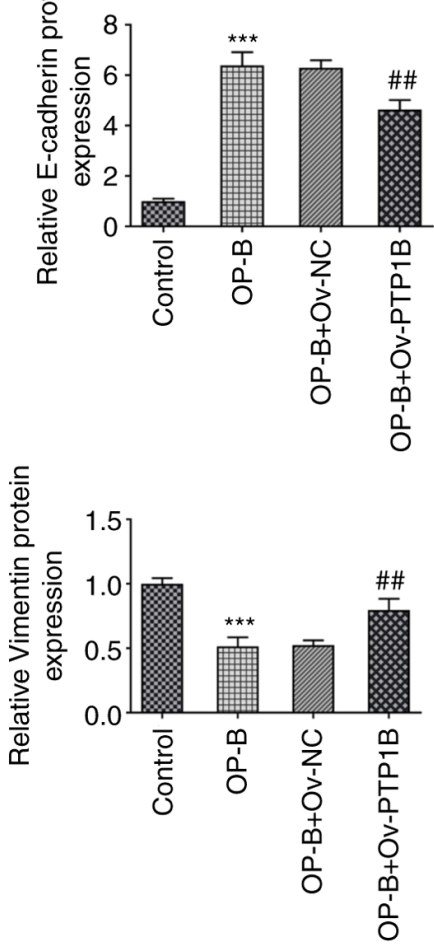
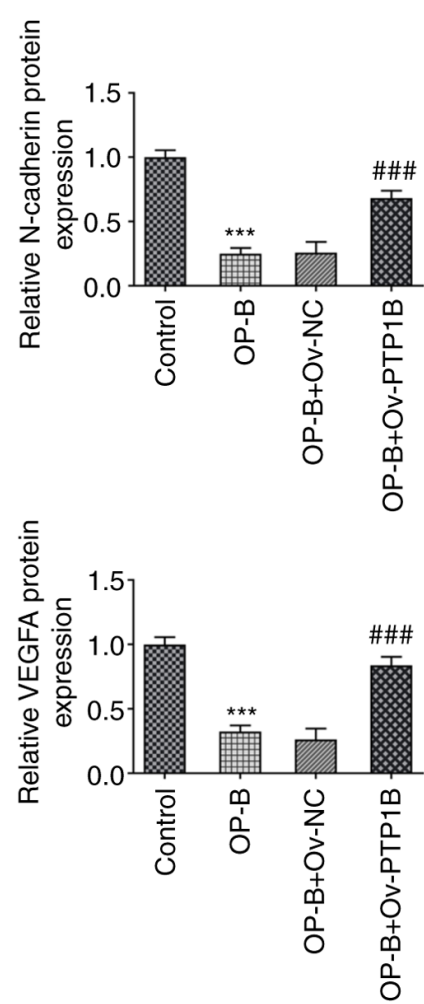

Figure 4. Effect of OP-B treatment and PTP1B overexpression on migration, invasion and angiogenesis of hepatocellular carcinoma cells. MHCC97-H cells were transfected with Ov-PTP1B or OV-NC and subsequently treated with $20 \mu \mathrm{M}$ OP-B. (A) Cell migration was determined by wound healing assay. (B) Transwell assay was performed to observe cell invasion. (C) Tube formation assay was used to assess cell angiogenesis. (D) Protein expression levels of E-cadherin, N-cadherin, Vimentin and VEGFA were detected by western blot analysis. ${ }^{* * *} \mathrm{P}<0.001$ vs. control; ${ }^{\# \#} \mathrm{P}<0.01$ and ${ }^{\# \# \#} \mathrm{P}<0.001 \mathrm{vs}$. OP-B $+\mathrm{Ov}-\mathrm{NC}$. NC, negative control; OP-B, ophiopogonin-B; Ov, overexpression vector; PTP1B, protein tyrosine phosphatase 1B. 

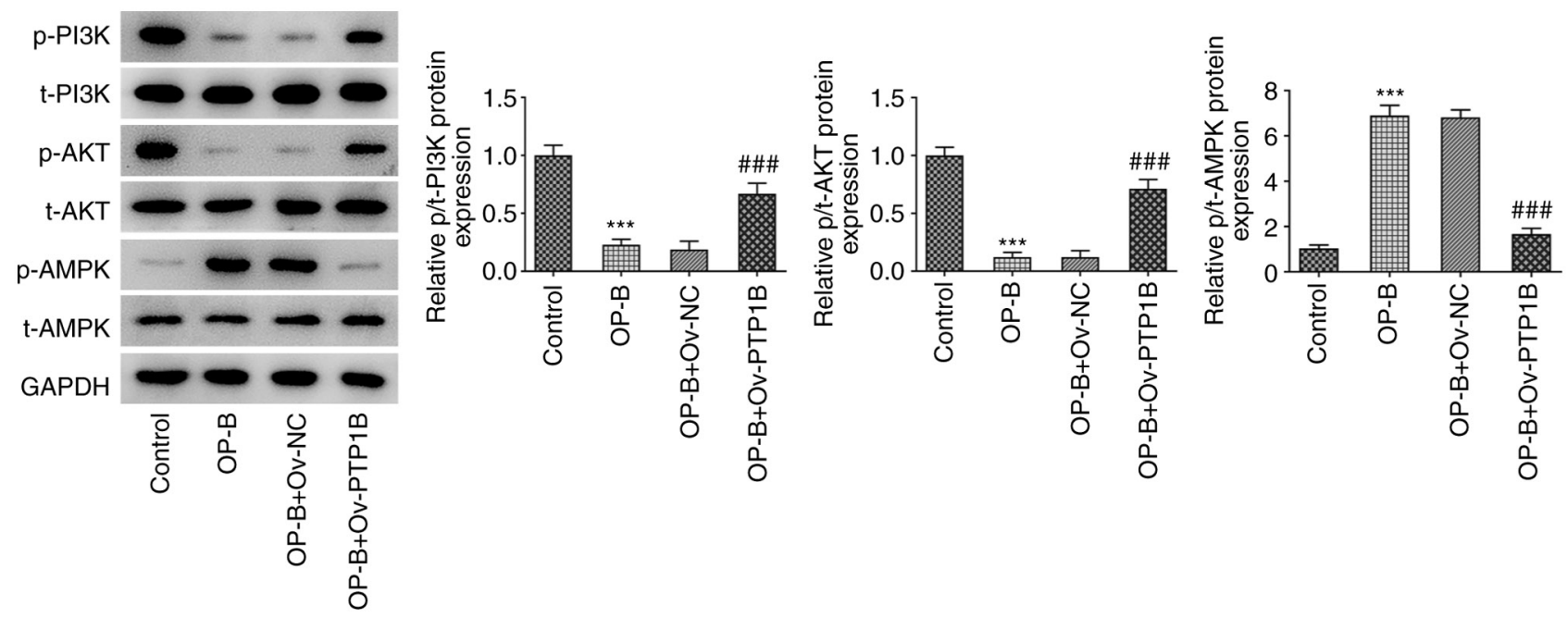

Figure 5. Effect of OP-B and PTP1B overexpression on PI3K/AKT and AMPK signaling in hepatocellular carcinoma cells. MHCC97-H cells were transfected with Ov-PTP1B or OV-NC and subsequently treated with $20 \mu \mathrm{M}$ OP-B, then the protein expression levels of components of the PI3K/AKT and AMPK

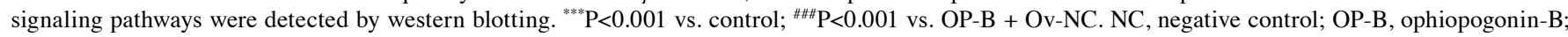
Ov, overexpression vector; PTP1B, protein tyrosine phosphatase 1B.

toxic effect on mice; it did not affect the mental state, life activity and weight gain of rats with the exception of $75 \mathrm{mg} / \mathrm{kg}$ OP-B, which significantly reduced body weight at 21 days post-treatment and this may due to the significant reduction in tumor weight caused by $75 \mathrm{mg} / \mathrm{kg}$ OP-B treatment. Additionally, it was found that in HCC xenograft tumors, OP-B effectively inhibited the growth of tumor and the expression of $\mathrm{Ki67,} \mathrm{CD31} \mathrm{and} \mathrm{VEGFA.} \mathrm{In} \mathrm{in} \mathrm{vitro} \mathrm{experiments,} \mathrm{OP-B} \mathrm{did}$ not affect the cell viability of normal hepatocyte HHL-5, but significantly impaired that of the HCC cell line MHCC97-H. Meanwhile, it was observed that $40 \mu \mathrm{M}$ OP-B reduced the cell viability of MHCC $97-\mathrm{H}$ to less than $50 \%$, indicating the excessive toxicity caused by $40 \mu \mathrm{M}$ OP-B. Thus 5,10 and $20 \mu \mathrm{M}$ OP-B was utilized for subsequent functional analysis and results showed that treatment with OP-B significantly suppressed proliferation, migration, invasion and angiogenesis, but induced apoptosis of HCC cells. In addition, the expression of E-cadherin was enhanced and that of N-cadherin, vimentin and VEGFA was decreased upon OP-B treatment. Ki67 is a well-known cell proliferation marker; CD31 is a well-known marker of endothelial cells and a key factor for adhesion and accumulation of platelets (26); VEGFA is the key regulator of angiogenesis during the growth of solid tumors (26). Loss of E-cadherin expression results in loss of contact inhibition and is associated with increased cell motility and advanced stages of cancer (27); N-cadherin and Vimentin are recognized as a markers for epithelial-mesenchymal transition (EMT) (28). Consistently, the in vivo and in vitro results of the present study demonstrated the anticancer effect of OP-B on HCC.

To uncover the mechanism through which OP-B exert its anticancer effect, its potential downstream targets were predicted using SwissTargetPrediction online database and PTP1B was identified as one of the targets of OP-B (data not shown). Notably, the participation of PTP1B in liver cancer initiation and progression has been previously reported $(15,29,30)$. Results from the present study showed that OP-B reduced the expression of PTP1B both in HCC tumor tissues and in cells in a concentration-depend manner. It was therefore speculated that OP-B may suppress the progression of HCC by targeting PTP1B. Further functional analysis revealed that overexpression of PTP1B significantly reversed the effect of OP-B treatment on malignant processes of HCC cells, indicating that $\mathrm{PTP} 1 \mathrm{~B}$ downregulation may be responsible for the anticancer effect of OP-B on HCC.

Finally, the mechanisms underlying the actions of OP-B/PTP1B in HCC were uncovered. Jin et al (31) reported that PTP1B promoted the progression of glioma by activating the MAPK/ERK and PI3K/AKT pathways. Xu et al (32) demonstrated that inhibition of PTP1B blocked pancreatic cancer progression by targeting the PKM2/AMPK/mTOC1 pathway. OP-B was also found to inhibit the PI3K/Akt signaling pathway in non-small cell lung cancer cells (20). The PI3K/AKT pathway had been extensively studied and found to be commonly activated in human cancer. Inhibition of this pathway leads to regression of human tumors (33). AMPK signaling is generally considered a key effector that mediates the tumor-suppressive function of liver kinase B1 (34). The inhibition of PI3K/AKT pathway or the activation of AMPK pathway has been found to inhibit proliferation, migration, invasion and EMT of cancer cells by regulating the expression of related markers such as Ki67, CD31, VEGFA, E-cadherin, N-cadherin and Vimentin (35-37). In the present study, OP-B inhibited the phosphorylation of PI3K/AKT and enhanced the phosphorylation of AMPK, whereas PTP1B overexpression reversed the effect of OP-B on the PI3K/AKT and AMPK signaling pathways. Although the present results were opposite with certain previous studies $(38,39)$, which showed that PTP1B inhibited the phosphorylation of PI3K/AKT signaling, the effect of PTP1B on PI3K/AKT and AMPK phosphorylation in cancer cells was demonstrated for the first time, to the best of our knowledge. Further studies are required to investigate whether it is due to the particularity of cancer cells compared with normal healthy cells that led to this opposite finding. Combined with previous findings (11), it was demonstrated that OP-B could indeed suppress the malignant processes of HCC through 
regulating multiple pathways. However, the involvement of the PI3K/AKT and AMPK signaling pathways needs further validation using an agonist or antagonist of these two pathways. Whether OP-B could inhibit HCC through regulating other pathways involved in HCC progression, such as TGF- $\beta$, mTOR and Wnt/ $\beta$-catenin signaling pathways (40-42) needs to be elucidated in future studies.

Collectively, the present study demonstrated that OP-B suppressed the progression of $\mathrm{HCC}$ both in vivo and in vitro through targeting PTP1B. Additionally, the PI3K/AKT and AMPK signaling pathways may be involved in this effect. These results may provide insight into the underlying mechanism involved in the antitumor effects of OP-B on HCC and may support the application of OP-B in a clinical setting.

\section{Acknowledgements}

Not applicable.

\section{Funding}

The present study was supported by the Basic Research on Medical and Health Application of Suzhou Science and Technology Program (grant no. sys2018003).

\section{Availability of data and materials}

The datasets used and/or analyzed during the current study are available from the corresponding author on reasonable request.

\section{Authors' contributions}

JS and YZ conceived and designed the study. FY, QG and HT performed the experiments. FY and QG analyzed and interpreted the data. JS and YZ drafted the manuscript and revised it for critically important intellectual content. JS and YZ confirm the authenticity of all the raw data. All authors have read and approved the final manuscript.

\section{Ethics approval and consent to participate}

The animal study protocol was approved by the Ethics Committee of Suzhou Hospital of Integrated Traditional Chinese and Western Medicine (Suzhou, China; approval no. 20180901).

\section{Patient consent for publication}

Not applicable.

\section{Competing interests}

The authors declare that they have no competing interests.

\section{References}

1. Villanueva A: Hepatocellular carcinoma. N Engl J Med 380: 1450-1462, 2019.

2. Grandhi MS, Kim AK, Ronnekleiv-Kelly SM, Kamel IR, Ghasebeh MA and Pawlik TM: Hepatocellular carcinoma: From diagnosis to treatment. Surg Oncol 25: 74-85, 2016.
3. Hartke J, Johnson M and Ghabril M: The diagnosis and treatment of hepatocellular carcinoma. Semin Diagn Pathol 34: 153-159, 2017.

4. Sim HW and Knox J: Hepatocellular carcinoma in the era of immunotherapy. Curr Probl Cancer 42: 40-48, 2018.

5. Liao X, Bu Y and Jia Q: Traditional Chinese medicine as supportive care for the management of liver cancer: Past, present, and future. Genes Dis 7: 370-379, 2020.

6. Li HM: Microcirculation of liver cancer, microenvironment of liver regeneration, and the strategy of Chinese medicine. Chin J Integr Med 22: 163-167, 2016.

7. Zhang S, Li H, Li L, Gao Q, Gu L, Hu C, Chen M and Zhang X Ophiopogonin B inhibits migration and invasion in non-small cell lung cancer cells through enhancing the interaction between Axin and $\beta$-catenin. J Cancer 12: 6274-6284, 2021.

8. Gao GY, Ma J, Lu P, Jiang X and Chang C: Ophiopogonin B induces the autophagy and apoptosis of colon cancer cells by activating JNK/c-Jun signaling pathway. Biomed Pharmacother 108: 1208-1215, 2018.

9. Zhang W, Zhang Q, Jiang Y, Li F and Xin H: Effects of ophiopogonin B on the proliferation and apoptosis of SGC-7901 human gastric cancer cells. Mol Med Rep 13: 4981-4986, 2016.

10. Yuan S, Xu Y, Yi T and Wang H: The anti-tumor effect of OP-B on ovarian cancer in vitro and in vivo, and its mechanism: An investigation using network pharmacology-based analysis. J Ethnopharmacol 283: 114706, 2021.

11. Shi J, Zhu L, Tang HL, Zhou YQ, Xue BY and Chen C: Ophiopogonin Binduceshepatocellular carcinoma MHCC97-H cell apoptosis and decreases invasion through inhibition of the JAK2/STAT3 signaling pathway. Int J Clin Exp Med 11: 1825-1834, 2018

12. Kumar A, Rana D, Rana R and Bhatia R: Protein tyrosine phosphatase (PTP1B): A promising drug target against life-threatening ailments. Curr Mol Pharmacol 13: 17-30, 2020.

13. Sharma B, Xie L, Yang F, Wang W, Zhou Q, Xiang M, Zhou S, Lv W, Jia Y, Pokhrel L, et al: Recent advance on PTP1B inhibitors and their biomedical applications. Eur J Med Chem 199: 112376, 2020.

14. Xu X, Tao Y, Niu Y, Wang Z, Zhang C, Yu Y and Ma L: miR-125a-5p inhibits tumorigenesis in hepatocellular carcinoma. Aging 11: 7639-7662, 2019.

15. Yang Q, Zhang L, Zhong Y, Lai L and Li X: miR-206 inhibits cell proliferation, invasion, and migration by down-regulating PTP1B in hepatocellular carcinoma. Biosci Rep 39: BSR20181823, 2019.

16. Daina A, Michielin O and Zoete V: SwissTargetPrediction: Updated data and new features for efficient prediction of protein targets of small molecules. Nucleic Acids Res 47: W357-W364, 2019.

17. Chen M, Guo Y, Zhao R, Wang X, Jiang M, Fu H and Zhang X: Ophiopogonin B induces apoptosis, mitotic catastrophe and autophagy in A549 cells. Int J Oncol 49: 316-324, 2016.

18. Chen M, Hu C, Guo Y, Jiang R, Jiang H, Zhou Y, Fu H, Wu M and Zhang X: Ophiopogonin B suppresses the metastasis and angiogenesis of A549 cells in vitro and in vivo by inhibiting the EphA2/Akt signaling pathway. Oncol Rep 40: 1339-1347, 2018.

19. Livak KJ and Schmittgen TD: Analysis of relative gene expression data using real-time quantitative PCR and the 2(-Delta Delta $\mathrm{C}(\mathrm{T})$ ) method. Methods 25: 402-408, 2001

20. Chen M, Du Y, Qui M, Wang M, Chen K, Huang Z, Jiang M, Xiong F, Chen J, Zhou J, et al: Ophiopogonin B-induced autophagy in non-small cell lung cancer cells via inhibition of the PI3K/Akt signaling pathway. Oncol Rep 29: 430-436, 2013.

21. Liu X, Li M, Wang X, Dang Z, Yu L, Wang X, Jiang Y and Yang Z: Effects of adjuvant traditional Chinese medicine therapy on long-term survival in patients with hepatocellular carcinoma. Phytomedicine 62: 152930, 2019.

22. Liu C, Yang S, Wang K, Bao X, Liu Y, Zhou S, Liu H, Qiu Y, Wang $\mathrm{T}$ and $\mathrm{Yu} \mathrm{H}$ : Alkaloids from traditional Chinese medicine against hepatocellular carcinoma. Biomed Pharmacother 120: 109543, 2019.

23. Wang M, Ye Q, Mao D and Li H: Research progress in liverregenerating microenvironment and DNA methylation in hepatocellular carcinoma: The role of traditional Chinese medicine. Med Sci Monit 26: e920310, 2020.

24. Gong Y: Identifying the targets for treatment of liver fibrosis and hepatocellular carcinoma from both western medicine and Chinese medicine. Chin J Integr Med 18: 245-249, 2012

25. Yen Y, So S, Rose M, Saif MW, Chu E, Liu SH, Foo A, Jiang Z, $\mathrm{Su} \mathrm{T}$ and Cheng YC: Phase I/II study of PHY906/capecitabine in advanced hepatocellular carcinoma. Anticancer Res 29: 4083-4092, 2009. 
26. Menon SS, Guruvayoorappan C, Sakthivel KM and Rasmi RR: $\mathrm{Ki}-67$ protein as a tumour proliferation marker. Clin Chim Acta 491: 39-45, 2019.

27. Mendonsa AM, Na TY and Gumbiner BM: E-cadherin in contact inhibition and cancer. Oncogene 37: 4769-4780, 2018

28. Satelli A and Li S: Vimentin in cancer and its potential as a molecular target for cancer therapy. Cell Mol Life Sci 68: 3033-3046, 2011.

29. Bartolomé RA, Martín-Regalado Á, Jaén M, Zannikou M, Zhang P, de Los Ríos V, Balyasnikova IV and Casal JI: Protein tyrosine phosphatase-1B inhibition disrupts IL13R $\alpha 2$-promoted invasion and metastasis in cancer cells. Cancers (Basel) 12: 500, 2020.

30. Tai WT, Chen YL, Chu PY, Chen LJ, Hung MH, Shiau CW, Huang JW, Tsai MH and Chen KF: Protein tyrosine phosphatase 1B dephosphorylates PITX1 and regulates p120RasGAP in hepatocellular carcinoma. Hepatology 63: 1528-1543, 2016.

31. Jin T, Li D, Yang T, Liu F, Kong J and Zhou Y: PTPN1 promotes the progression of glioma by activating the MAPK/ERK and $\mathrm{PI} 3 \mathrm{~K} / \mathrm{AKT}$ pathways and is associated with poor patient survival. Oncol Rep 42: 717-725, 2019.

32. Xu Q, Wu N, Li X, Guo C, Li C, Jiang B, Wang H and Shi D: Inhibition of PTP1B blocks pancreatic cancer progression by targeting the PKM2/AMPK/mTOC1 pathway. Cell Death Dis 10: $874,2019$.

33. Alzahrani AS: PI3K/Akt/mTOR inhibitors in cancer: At the bench and bedside. Semin Cancer Biol 59: 125-132, 2019.

34. Yuan J, Dong X, Yap J and Hu J: The MAPK and AMPK signalings: Interplay and implication in targeted cancer therapy. J Hematol Oncol 13: 113, 2020.

35. Zhang B, Wu J, Guo P, Wang Y, Fang Z, Tian J, Yu Y, Teng W, Luo Y and Li Y: Down-regulation of SREBP via PI3K/AKT/mTOR pathway inhibits the proliferation and invasion of non-small-cell lung cancer cells. Onco Targets Ther 13: 8951-8961, 2020.
36. Wu J, Zhao X, Sun Q, Jiang Y, Zhang W, Luo J and Li Y: Synergic effect of PD-1 blockade and endostar on the PI3K/AKT/mTOR-mediated autophagy and angiogenesis in Lewis lung carcinoma mouse model. Biomed Pharmacother 125: 109746, 2020.

37. Zhang Q, Kong J, Dong S, Xu W and Sun W: Metformin exhibits the anti-proliferation and anti-invasion effects in hepatocellular carcinoma cells after insufficient radiofrequency ablation. Cancer Cell Int 17: 48, 2017.

38. Li H, Dusseault J and Larose L: Nck1 depletion induces activation of the PI3K/Akt pathway by attenuating PTP1B protein expression. Cell Commun Signal 12: 71, 2014.

39. Sun T, Wang Q, Yu Z, Zhang Y, Guo Y, Chen K, Shen X and Jiang H: Hyrtiosal, a PTP1B inhibitor from the marine sponge Hyrtios erectus, shows extensive cellular effects on PI3K/AKT activation, glucose transport, and TGFbeta/Smad2 signaling. Chembiochem 8: 187-193, 2007.

40. Chen J, Gingold JA and Su X: Immunomodulatory TGF- $\beta$ signaling in hepatocellular carcinoma. Trends Mol Med 25: 1010-1023, 2019.

41. Ferrín G, Guerrero M, Amado V, Rodríguez-Perálvarez $M$ and De la Mata M: Activation of mTOR signaling pathway in hepatocellular carcinoma. Int J Mol Sci 21: 1266, 2020.

42. Vilchez V, Turcios L, Marti F and Gedaly R: Targeting Wnt/ $\beta$-catenin pathway in hepatocellular carcinoma treatment. World J Gastroenterol 22: 823-832, 2016. 